\title{
Bacillus amyloliquefaciens GAI as a source of potent antibiotics and other secondary metabolites for biocontrol of plant pathogens Anthony Arguelles-Arias ${ }^{1}$, Marc Ongena ${ }^{2}$, Badre Halimi ${ }^{3}$, Yannick Lara ${ }^{4}$, Alain Brans ${ }^{1}$, Bernard Joris ${ }^{1}$ and Patrick Fickers*1
}

\author{
Address: ${ }^{1}$ Centre for Protein Engineering, Physiology and Bacterial Genetics, University of Liege, 4000 Liege, Belgium, ${ }^{2}$ Walloon Centre for \\ Industrial Biology, Bio-Industry Unit, Gembloux Agro-Bio Tech, University of Liege, B-5030 Gembloux, Belgium, ${ }^{3}$ Walloon Centre for Industrial \\ Biology, Microbial Technology Unit, University of Liege, 4000 Liege, Belgium and ${ }^{4}$ Centre for Protein Engineering, Cyanobacteria Group, \\ University of Liege, 4000 Liege, Belgium \\ Email: Anthony Arguelles-Arias - aarguelles@doct.ulg.ac.be; Marc Ongena - ongena.m@fsagx.ac.be; Badre Halimi - BE.halimi@doct.ulg.ac.be; \\ Yannick Lara - ylara@ulg.ac.be; Alain Brans - abrans@ulg.ac.be; Bernard Joris - bjoris@ulg.ac.be; Patrick Fickers* - pfickers@ulb.ac.be \\ * Corresponding author
}

Published: 26 November 2009

Microbial Cell Factories 2009, 8:63
Received: 6 October 2009

Accepted: 26 November 2009

(C) 2009 Arguelles-Arias et al; licensee BioMed Central Ltd.

This is an Open Access article distributed under the terms of the Creative Commons Attribution License (http://creativecommons.org/licenses/by/2.0), which permits unrestricted use, distribution, and reproduction in any medium, provided the original work is properly cited.

\begin{abstract}
Background: Phytopathogenic fungi affecting crop and post-harvested vegetables are a major threat to food production and food storage. To face these drawbacks, producers have become increasingly dependent on agrochemicals. However, intensive use of these compounds has led to the emergence of pathogen resistance and severe negative environmental impacts. There are also a number of plant diseases for which chemical solutions are ineffective or non-existent as well as an increasing demand by consumers for pesticide-free food. Thus, biological control through the use of natural antagonistic microorganisms has emerged as a promising alternative to chemical pesticides for more rational and safe crop management.
\end{abstract}

Results: The genome of the plant-associated B. amyloliquefaciens GAI was sample sequenced. Several gene clusters involved in the synthesis of biocontrol agents were detected. Four gene clusters were shown to direct the synthesis of the cyclic lipopeptides surfactin, iturin $A$ and fengycin as well as the iron-siderophore bacillibactin. Beside these non-ribosomaly synthetised peptides, three additional gene clusters directing the synthesis of the antibacterial polyketides macrolactin, bacillaene and difficidin were identified. Mass spectrometry analysis of culture supernatants led to the identification of these secondary metabolites, hence demonstrating that the corresponding biosynthetic gene clusters are functional in strain GAI. In addition, genes encoding enzymes involved in synthesis and export of the dipeptide antibiotic bacilysin were highlighted. However, only its chlorinated derivative, chlorotetaine, could be detected in culture supernatants. On the contrary, genes involved in ribosome-dependent synthesis of bacteriocin and other antibiotic peptides were not detected as compared to the reference strain B. amyloliquefaciens FZB42.

Conclusion: The production of all of these antibiotic compounds highlights $B$. amyloliquefaciens $\mathrm{GAI}$ as a good candidate for the development of biocontrol agents. 


\section{Background}

Phytopathogenic fungi affecting crop and post-harvested vegetables are a major threat to food production and food storage. Worldwide, this has led to important economic losses, particularly over the past few decades as agricultural production has intensified. Post-harvest food spoilage also represents a potential health hazard for humans due to the production by phytopathogens of toxic metabolites in the affected sites [1]. To face these drawbacks, producers have become increasingly dependent on agrochemicals. However, intensive use of these compounds has led to the emergence of pathogen resistance and severe negative environmental impacts. There are also a number of plant diseases for which chemical solutions are ineffective or non-existent as well as an increasing demand by consumers for pesticide-free food. Thus, biological control through the use of natural antagonistic microorganisms has emerged as a promising alternative to chemical pesticides for more rational and safe crop management. There is a large body of literature reporting the potential use of rhizosphere-associated bacteria in stimulating plant growth and biocontrol agents [2-4]. Among them, several strains belonging to the genus Bacillus and particularly to the B. subtilis and B. amyloliquefaciens species were reported effective for the biocontrol of multiple plant diseases caused by soilborne $[5,6]$ or post-harvest pathogens [7-9]. Members of the Bacillus genus are thus among the beneficial bacteria mostly exploited as microbial biopesticides. Bacillus-based products represent about half of the commercially available bacterial biocontrol agents [10].

From a global viewpoint, the beneficial protective effect of these agents may rely on different mechanisms. By taking benefit from the nutrients secreted by the plant root, these bacteria efficiently colonise root systems and the surrounding soil layer (rhizosphere). In turn, they beneficially influence the plant through direct growth stimulation and/or by protecting it from infection by phytopathogens. Antibiosis through the production of antifungal metabolites and antibiotics is probably the best known and most important mechanism used by biocontrol bacteria to limit pathogen invasion in host plant tissues. Competition for iron traces in soils through siderophore production has also been postulated to be an important mechanism for the biocontrol activity of some rhizobacteria [11]. Another important mechanism relies on the ability of some strains to activate defence systems in the host plant. In other words, the beneficial bacterium can trigger a systemic resistance reaction that renders the host less susceptible to subsequent infection in distal tissues. This long-lasting phenomenon has been termed rhizobacteria-induced systemic resistance (ISR).
It is well known that some Bacillus species may synthesise numerous antimicrobial or, more generally, bioactive compounds with well-established activity in vitro [12]. However, except for a very limited number of strains $[13,14]$, few studies that relate the global potential for antibiotic production with the biocontrol activity of a particular Bacillus strain have been reported. In this context, the B. amyloliquefaciens strain GA1 (formerly B. subtilis GA1, see below) displays high in vitro inhibitory activity toward growth of multiple fungal and oomycete plant pathogens [15]. When used as seed treatment, strain GA1 was shown to alleviate seedling diseases through direct antibiosis against soilborne pathogens (unpublished data). The strain was also shown to reduce post-harvest infection of apples caused by $B$. cinerea, the causative agent of grey mold disease [15]. These data suggest the secretion of multiple antibiotics and demonstrate the potential application of B. amyloliquefaciens GA1 as a biocontrol agent. In the present work, the genome of strain GA1 was sample sequenced to better characterise the genetic determinants directing the synthesis of antimicrobial metabolites that could be used in the field.

\section{Results \\ Strain identification}

The $r e c N$ and recA sequences from strain GA1 had $83 \%$ and $98 \%$ identity, respectively, with the sequence of $B$. amyloliquefaciens FZB42, while scores of $68 \%$ and $84 \%$ were obtained for B. subtilis. The phylogenetic tree (figure 1) constructed using cancatenated $\operatorname{rec} A$ and $\operatorname{rec} N$ sequences of related members of the Bacillus genus revealed that strain GA1 grouped with $B$. amyloliquefaciens FZB42 and is phylogenetically separated from B. subtilis. However, the phylogenetic tree suggests that the two strains are somewhat distant genetically.

\section{Genome analysis}

Sequencing 500 clones from a shotgun library led to the determination of $461.5 \mathrm{~kb}$ of the B. amyloliquefaciens GAI chromosome and the identification of 358 protein-coding sequences. These presented, on average, $89 \%$ identity on amino acid level with that of B. amyloliquefaciens FZB42 and $76 \%$ with that of $B$. subtilis. Among these sequences, the partial ORFs of eight giant gene clusters directing the synthesis of bioactive peptides and polyketides by modularly organised mega-enzymes, the so-called non-ribosomal peptide synthetase (NRPS) and polyketide synthetase (PKS), were identified (figure 2). In addition, the sfp gene coding for a 4 '-phosphopantetheinyl transferase responsible for the conversion of the apo-ACP domains of PKS and NRPS to their active holo-forms, was also detected in strain GA1 together with the regulatory gene $y c z E$ (data not shown). 


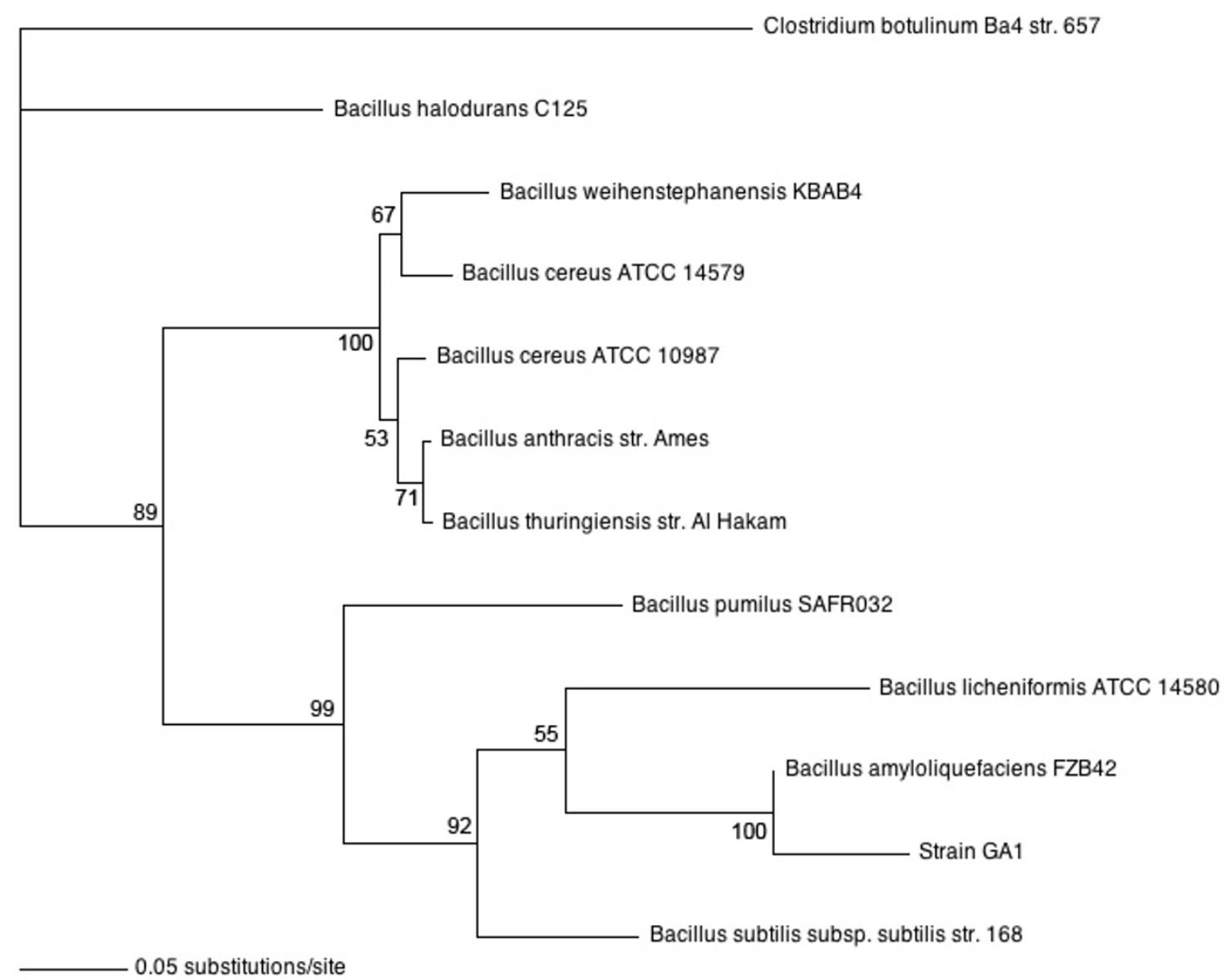

\section{Figure I}

Likelihood phylogenetic tree depicting the phylogenetic relationship between strain GAI and other representatives of the Bacillus genera: B. amyloliquefaciens FZB42 (NC_009725), B. anthracis str. Ames (NC_003997), B. cereus ATCC 10987 (NC_003909) B. cereus ATCC 14579 (NC_004722), B. halodurans C-I 25 (BA_000004), B. licheniformis ATCC I 4580 (NC_006270), B. pumilus SAFR-032 (NC_009848), B. subtilis subsp. subtilis str. I 68 (NC_000964), B. thuringiensis str. Al Hakam (NC_008600), B. weihenstephanensis KBAB4 (NC_0I0I84). All sequences were aligned on Clostridium botulinum Ba4 str. 657 (NC_0I 2658). Values for frequencies less than $50 \%$ are not given. The scale bars represent the number of substitutions per base position.

Fourteen gene fragments with homology toward gene clusters directing the synthesis of cyclic lipopeptide were obtained (figure 2). Of these, eleven had a high amino acid identity with $\operatorname{srf}(80-96 \%)$ or fen $(41-92 \%)$ operon directing the synthesis of surfactin and fengycin in B. amyloliquefaciens FZB42. In strain GA1, the two gene clusters were found located in the same genetic environment as in strain FZB42 [13]; i.e. at the hxlR-CDS22 and yngL-dacC loci for $s r f$ and fen operon, respectively (figure 2). Similarly to B. amyloliquefaciens FZB42 and B. subtilis 168, the coms gene, encoding a competence signal molecule, was found embedded within $\operatorname{sr} A B$ (figure 2). Three gene fragments directing the synthesis of an iturin lipopeptide were also detected. These fragments presented $48-82 \%$ amino acid identity with the ituDABC operon encoding the iturin
A synthetase in B. subtilis RB14 [16]. In strain GA1, this operon was found located between the ORFs $x y n D$ and $y x j F$ (figure 2). In addition, five gene fragments presented a high amino acid identity (87-93\%) with the $d h b$ gene directing the synthesis of the siderophore bacillibactin in B. amyloliquefaciens FZB42. They were found at an exactly conserved locus, i.e. between CDS304 and yuilv ORFs (figure 2). By contrast, the $n r s$ operon directing the synthesis of a not yet identified NRPS peptide in B. amyloliquefaciens FZB42 [13] could not be detected by PCR techniques in strain GA1 (figure 3).

Several gene fragments involved in polyketide synthesis were also identified. Of these, thirteen presented a high amino acid identity with PKS genes directing the synthesis 


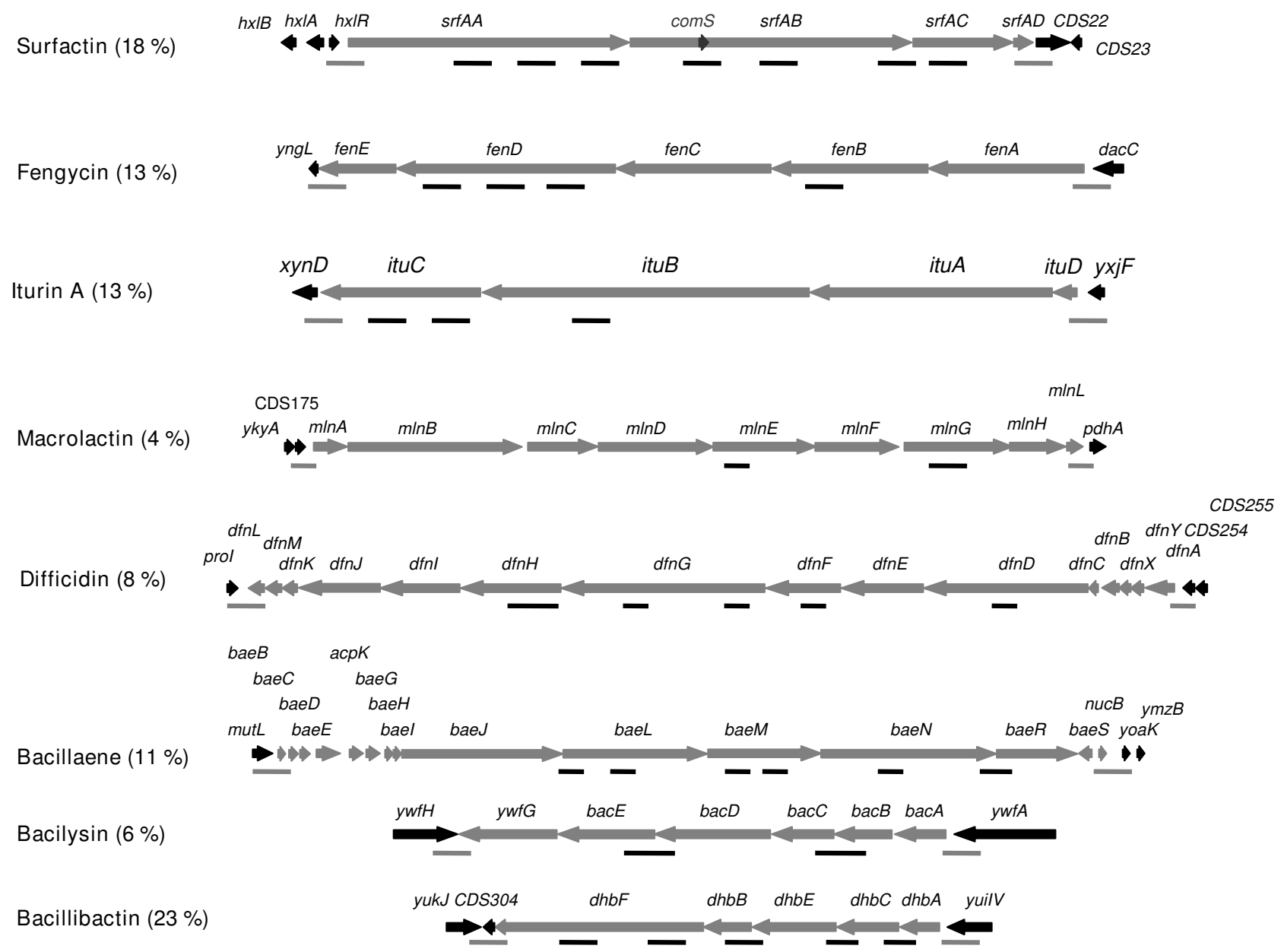

Figure 2

Overview of the different gene fragments identified in strain GAI. The grey arrows represent the different genes involved in the metabolite synthesis in B. amyloliquefaciens FZB42 while the black arrows represent the flanking genes. Black lines correspond to the gene fragments obtained during the sequencing of strain GAI, while grey lines indicate flanking regions amplified by PCR on strain GA I genomic DNA with primer pairs described in Table I. The values in parentheses give the percentage of the gene cluster determined in strain GAI.

of the antibacterial compounds macrolactin (86-98\%), difficidin (77-96\%) and bacillaene (84-96\%). In strain GA1, all these gene clusters were found to be collinear to that of B. amyloliquefaciens FZB42 [13]; i.e. between CDS175 and pdhA for macrolactin, proI and CDS254 for difficidin and mutl and yoak for bacillaene (figure 2).

In addition to these NRPS and PKS metabolites, genes involved in the synthesis of ribosomaly synthetised antibacterial compounds were detected in strain GA1. Indeed, their deduced amino acid sequence presented high identity (76-100\%) with bacB, bacC, bacD and bacE genes encoding enzymes responsible for the synthesis and export of the di-peptide bacilysin, and were found located between ORFs $y w f H$ and $y w f A$ as in FZB42 strain. By con- trast, none of the genes involved in $B$. amyloliquefaciens FZB42 in the resistance toward the bacteriocin mersacidin, nor those directing the biosynthesis of the cyclic bacteriocin subtilosin found in some strains of $B$. amyloliquefaciens could be detected by PCR techniques in strain GA1 (figure 4) [13,17].

\section{Analysis of the NRPS and PKS product of B. amyloliquefaciens GAI}

Culture supernatants of B. amyloliquefaciens GA1 collected after 12 and $72 \mathrm{~h}$ of growth in Landy medium were concentrated by solid phase extraction and analysed by HPLC-ESI-MS. For samples collected after $72 \mathrm{~h}$, three groups of mass peaks were detected (Table 1). Signals at $\mathrm{m} / \mathrm{z}$ from 1030.8 to 1074.8 and from 1471.9 to 1543.8 
Table I: Metabolite production of B. amyloliquefaciens GAI detected by HPLC-ESI mass spectrometry

\begin{tabular}{|c|c|c|c|}
\hline Metabolite & Observed mass peak & Assignment & Reference \\
\hline \multirow[t]{3}{*}{ Surfactin } & $1030.8,1046.8[\mathrm{M}+\mathrm{Na}, \mathrm{K}]+$ & CI3-surfactin & [28] \\
\hline & $1044.8,1060.8[\mathrm{M}+\mathrm{Na}, \mathrm{K}]+$ & Cl4-surfactin & {$[28]$} \\
\hline & $1058.8,1074.8[\mathrm{M}+\mathrm{Na}, \mathrm{K}]+$ & CI5-surfactin & {$[28]$} \\
\hline \multirow[t]{5}{*}{ Fengycin } & $|47| .9, \mid 487.9[\mathrm{M}+\mathrm{Na}, \mathrm{K}]+$ & Ala-6 CI5-fengycin & [28] \\
\hline & $1485.9,150 \mid .9[\mathrm{M}+\mathrm{Na}, \mathrm{K}]+$ & Ala-6 Cl6-fengycin & {$[28]$} \\
\hline & $1499.9,1515.9[\mathrm{M}+\mathrm{Na}, \mathrm{K}]+$ & Ala-6 CI7-fengycin & [28] \\
\hline & $1513.9,1529.9[\mathrm{M}+\mathrm{Na}, \mathrm{K}]+$ & Val-6 Cl6-fengycin & [28] \\
\hline & $1527.8,1543.8[\mathrm{M}+\mathrm{Na}, \mathrm{K}]+$ & Val-6 Cl7-fengycin & {$[28]$} \\
\hline \multirow[t]{2}{*}{ Iturin A } & $1066.1[\mathrm{M}+\mathrm{Na}]+$ & Cl4-iturin A & [28] \\
\hline & I079.7 $[\mathrm{M}+\mathrm{Na}]+$ & CI5-iturin A & [28] \\
\hline \multirow[t]{4}{*}{ Macrolactin } & $425.4[\mathrm{M}+\mathrm{Na}]+$ & Macrolactin A28 & [19] \\
\hline & $511.4[\mathrm{M}+\mathrm{Na}]+$ & 7-o-malonyl macrolactin A & {$[19]$} \\
\hline & $525.4[\mathrm{M}+\mathrm{Na}]+$ & 7-o-succinyl macrolactin A & {$[19]$} \\
\hline & $629.3[\mathrm{M}+\mathrm{H}-\mathrm{H} 2 \mathrm{O}]+$ & Macrolactin D & {$[19]$} \\
\hline Difficidin & $559.2[\mathrm{M}-\mathrm{H}]-$ & Oxydifficidin & [18] \\
\hline \multirow[t]{2}{*}{ Bacillaene } & $583.5[\mathrm{M}+\mathrm{H}]+$ & Bacillaene A & {$[18]$} \\
\hline & $605.5[\mathrm{M}+\mathrm{Na}]+$ & Bacillaene B & {$[18]$} \\
\hline \multirow[t]{2}{*}{ Chlorotetaine } & $289.2[\mathrm{M}+\mathrm{H}]+$ & Chlorotetaine $\left({ }^{35} \mathrm{Cl}\right)$ & [20] \\
\hline & $291.1[\mathrm{M}+\mathrm{H}]+$ & Chlorotetaine $\left({ }^{37} \mathrm{Cl}\right)$ & [20] \\
\hline
\end{tabular}

were identified as surfactins and fengycins on the basis of data obtained both from the literature and from the analysis of pure compounds. For fengycins, signals at $\mathrm{m} / \mathrm{z}$ of 1485.9 and 1513.9 and at 1499.9 and 1527.8 highlight an Ala/Val dimorphy at position 6 of the peptide ring for the $\mathrm{C} 16$ and $\mathrm{C} 17$ homologues, which is the characteristic trait of fengycin A and B. Mass peaks at $m / z 1066.1$ and 1079.7 were found in accordance with the calculated mass values of sodium adducts of the C14 and C15 homologues of iturin A. By contrast, no peaks corresponding to the calculated mass of the various bacillomycin $\mathrm{D}$ homologues or to those of mycosubtilin could be detected under these conditions. This suggests that the iturins produced by strain GA1 correspond to the iturin A group. MALDI-TOFMS analyses of crude supernatant were consistent with the mass patterns obtained by HPLC-ESI-MS (data not shown). From samples collected after $12 \mathrm{~h}$ of growth, signals at $m / z 425.4,511.4,525.4$ and 629.3 were assigned to the molecular ions of the antimicrobial polyketide macrolactin A, 7-o-malonyl macrolactin A, 7-o-succinyl macrolactin A and macrolactin D respectively, whereas signals at $m / z 559.2,583.5$ and 605.5 were assigned to oxydifficidin, bacillaene A and bacillaene B (Table 1) based on data from the literature $[18,19]$.

The production of siderophores by B. amyloliquefaciens GA1 was investigated by plating cells on CAS solid medium. After $72 \mathrm{~h}$ of incubation, the disappearance of the blue colour due to the ternary complex chrome azurol-S/iron (III)/hexadecyltrimethylammonium bromide in favour of a bright orange halo traduces the uptake of the ferric ions by the cells and thus the production of siderophore (i.e. bacillibactin) (data not shown).

\section{Production of antibacterial peptide}

HPLC-ESI-MS analysis of freeze-dried samples of culture in Basic 77 medium gave peaks at m/z 289.2 and 291.1, which represents the typical mass spectrometric signature of the dipeptide antibiotic chloroteatine, a chlorinated derivative of bacilysin (Table 1) [20]. Surprisingly, no mass peak corresponding to this latter compound could be detected under our conditions. When samples were analysed by MALDI-TOF mass spectrometry, none of the bacteriocin subtilosin, mercacidin or subtilin mass signals could be detected (data not shown).

\section{Discussion}

Recent taxonomic studies have revealed that $B$. subtilis is heterogeneous and should be considered as a group of closely related species [21]. In addition, B. subtilis and B. amyloliquefaciens are phenotypically similar and can be easily confused. Based on phenotypic and biochemical characterisations, strain GA1, initially isolated from strawberry cultures, was first assigned to B. subtilis (unpublished data, [15]). However, substantial molecular evidence suggested that the strain was more related to $B$. 

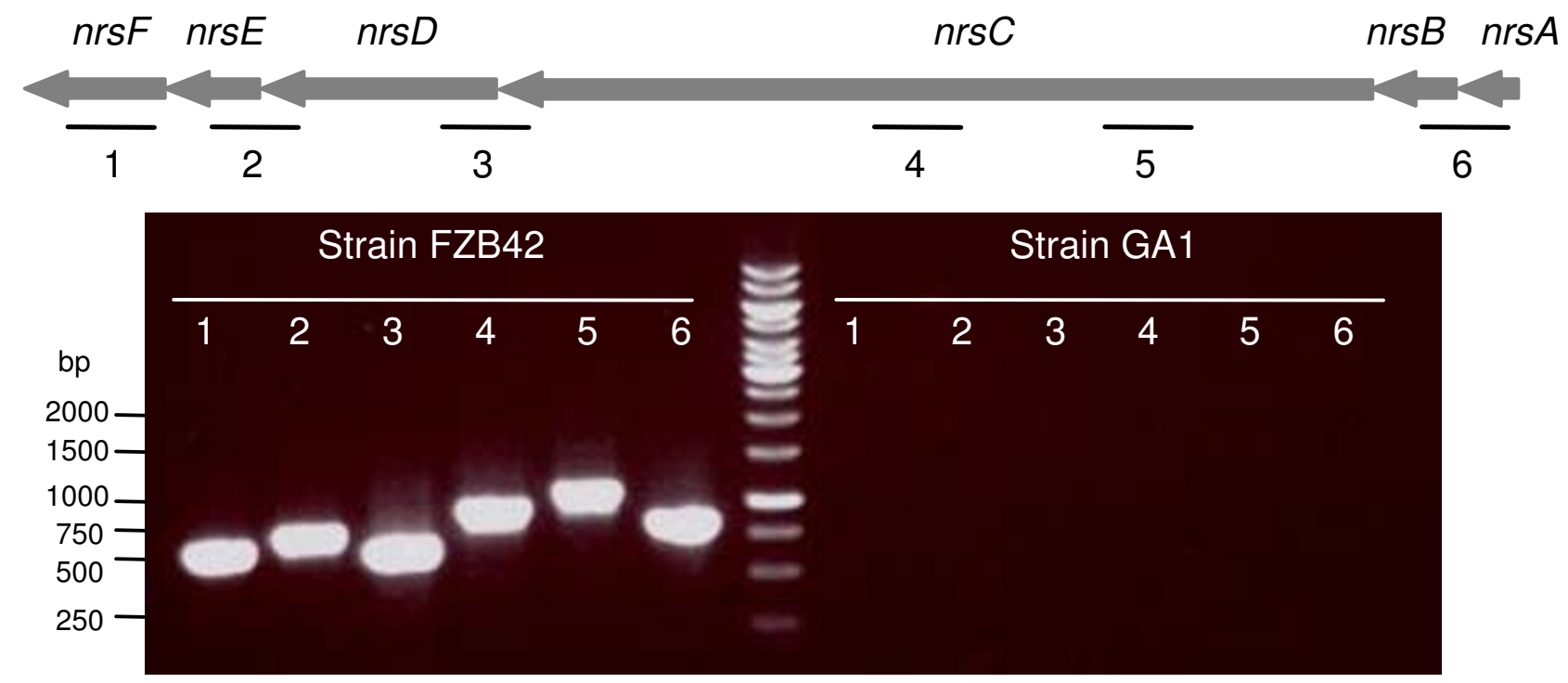

Figure 3

Detection of the nrs operon in B. amyloliquefaciens strains FZB42 and GAI. The grey arrows indicate the gene organisation in strain FZB42. The black lines represent the different gene fragments amplified by PCR using primer pairs as described in Table I.

amyloliquefaciens than to $B$. subtilis. Thus, to accurately characterise the strain taxonomically, $r e c A$ and $r e c N$ genes, encoding DNA repair and recombination proteins, were sequenced and used to construct a phylogenetic tree. These two genes were selected because they had previously been shown to be effective in resolving closely related taxa [22]. The obtained phylogenetic tree clearly demonstrates that strain GA1 should be assigned to $B$. amyloliquefaciens rather than $B$. subtilis. The higher level of identity obtained for the 358 protein-coding sequence detected in strain GA1 to that of $B$. amyloliquefaciens FZB42 is in accordance with this result.

Plant-associated bacteria are known to play a key role in plant health by stimulating their growth and protecting them from phytopathogens, with this related to the production of a vast array of biologically active NRPS and PKS secondary metabolites. These metabolites have the same mode of synthesis, the so-called multicarrier thiotemplate mechanism, in which small monomer units, aminoacids and aryl acid in NRPS and acyl-CoAs in PKS are loaded, activated and condensed by mega-enzymes organised in iterative functional units [23]. The aim of this work was to better genetically characterise B. amyloliquefaciens GA1, with particular emphasis on gene clusters encoding these mega-enzymes. As they are encoded by large operons of 55 to $80 \mathrm{~kb}$ for PKS and 18 to $42 \mathrm{~kb}$ for NRPS, randomly sequencing $10 \%$ of the genome yielded enough data to point out the presence of these gene clusters in strain GA1.

Among NRPS antibiotics, Bacillus amyloliquefaciens GA1 was found to produce surfactin, iturin A, fengycin A and fengycin B. These are cyclic lipopeptides (CLP) composed of seven (surfactin and iturin A) or $10 \alpha$-amino acids (fengycins) linked to a $\beta$-amino (iturins) or $\beta$-hydroxy (surfactins and fengycins) fatty acid which may vary from C-13 to C-16 for surfactins, from C-14 to C-17 for iturins and from C-14 to C-18 for fengycins. CLPs have well-recognized potential biotechnology and biopharmaceutical applications due notably to their surface-active properties $[24,25]$. These surfactants may also play different roles in the development and survival of Bacillus strains in their natural habitat: increasing bioavailability of hydrophobic water-insoluble substrates, heavy metal binding, bacterial pathogenesis, quorum sensing, motility, biofilm formation etc. [26,27]. Other works have highlighted additional traits that are also very important for the fitness of Bacillus in the rhizosphere and for its efficacy as biocontrol agent [28].

The ability of $B$. subtilis to efficiently colonise surfaces of plant roots is a prerequisite for phytoprotection. This process relies on surface motility and efficient biofilm formation of the Bacillus cell populations that evolve and behave as structured and coordinated microcolonies 
A
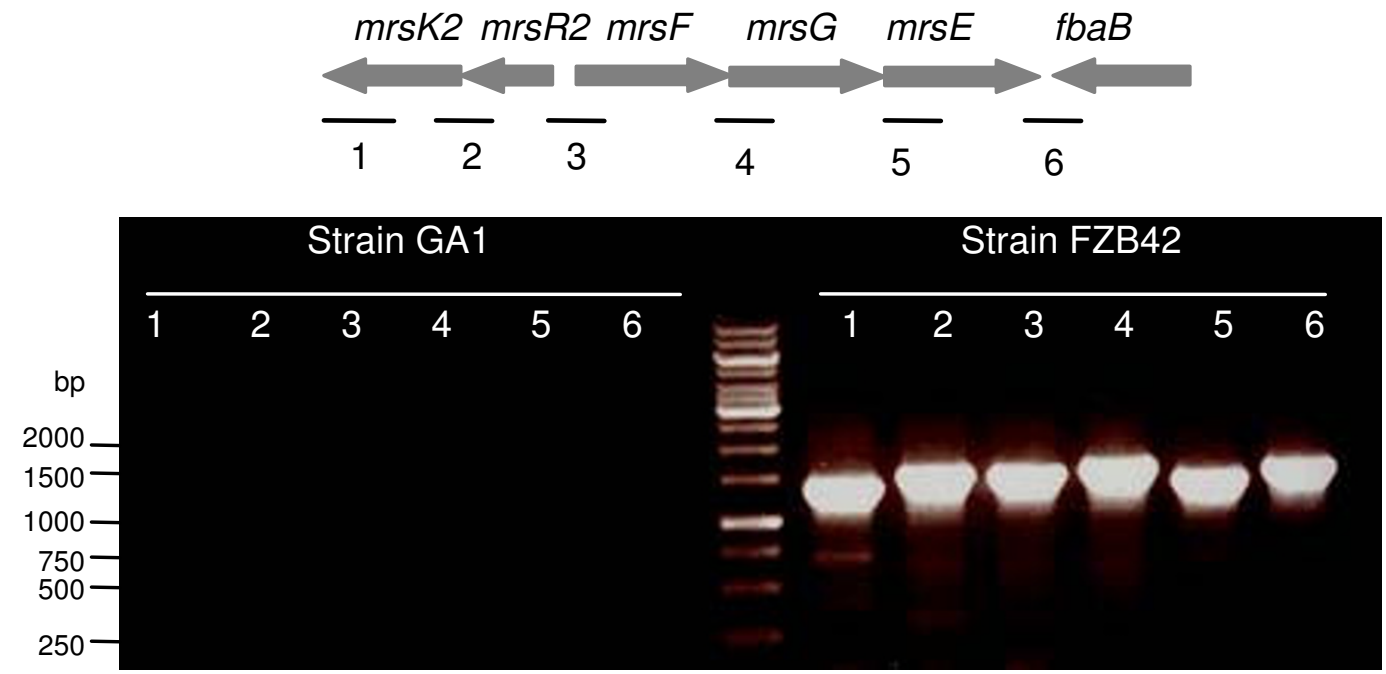

B

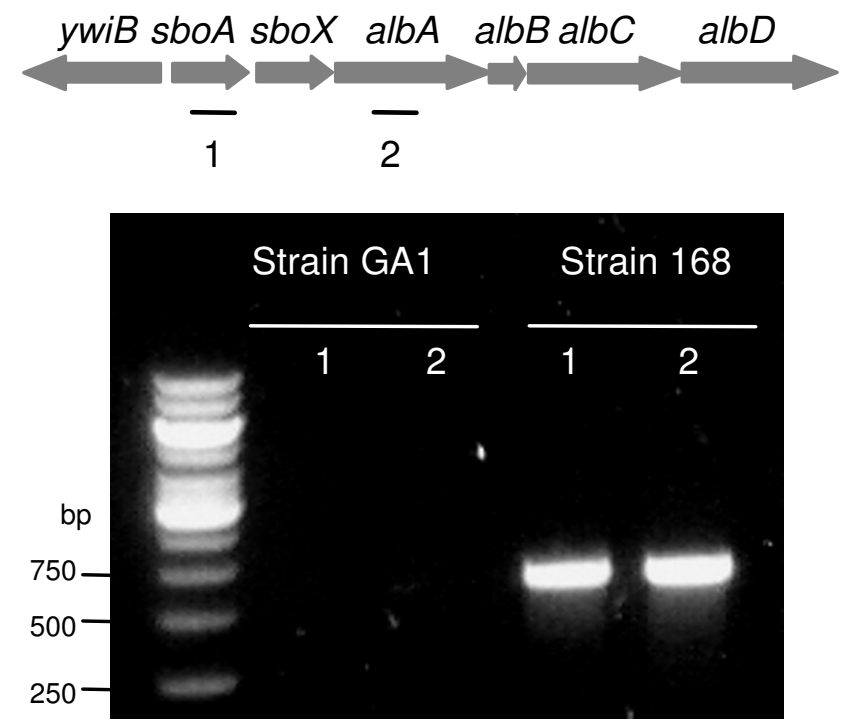

Figure 4

Detection of the gene cluster involved in resistance toward bacteriocins in B. amyloliquefaciens strains FZB42 and GAI (A) and those responsible for subtilosin synthesis, immunity and transport in $B$. subtilis 168 and $B$. amyloliquefaciens strains GAI. The grey arrows indicate the gene organisation in strain FZB42 (A) and I68 (B). The black lines represent the different gene fragments amplified by $P C R$ using primer pairs as described in Table

adhering to root and on soil particle surfaces [29]. By modifying cell surface properties, surfactin and iturin were reported to positively influence cell spreading, swarming and biofilm formation [30-33] and thus may globally favour plant root colonisation. Furthermore, iturins and fengycins display strong antifugal activity and are inhibitory for the growth of a wide range of plant pathogens. Surfactins are not fungitoxic in themselves but retain some synergistic effect on the antifungal activity of iturin A [34]. In the context of biocontrol, the involvement of CLPs in direct antagonism of phytopathogens is thus obvious and was demonstrated by testing the pure compounds in planta or by correlating the biocontrol activity and use of non-producing or overproducing derivatives $[5,35,36]$.

The role of fengycins produced by strain GA1 was demonstrated by the very effective disease control provided by 
treatment of fruits with CLP-enriched extracts and by in situ detection of fengycins in inhibitory amounts [15]. Another recently established role for lipopeptides from beneficial Bacillus isolates is the stimulation of the plant immune system [37]. Surfactins and, to a lesser extent, fengycins can induce a priming state in host plant which allows an accelerated activation of defense responses upon pathogen or insect attack, leading to an enhanced resistance to the attacker encountered [38]. Surfactins can be considered as a novel class of microbial-associated molecular patterns that can be specifically perceived by plant cells as signals to activate defense mechanisms [39]. The use of single strains evolving diverse mechanisms to reduce disease incidence is thus of prime interest. Bacillus isolates such as strain GA1 that co-produce the three CLP families should display such a multi-faceted biocontrol activity. That said, in strain GA1 the itu operon directing the synthesis of iturin A in B. subtilis RB14 [40] was surprisingly found inserted at exactly the same position as the expected bacylomycin D gene cluster from B. amyloliquefaciens FZB42 [32]. This suggests that an inter-species horizontal transfer of genes could have occurred between $B$. subtilis and B. amyloliquefaciens.

Besides lipopepides, a functional $d h b$ gene cluster was shown in strain GA1 to direct the synthesis of the catecholic siderophore bacillibactin, a cyclic trimeric lactone of the 2,3-dihydroxybenzoyl-Gly-Thr monomer unit. Siderophores are high affinity ferric iron chelators that enhance the microbial acquisition of this element in environments where its bioavailability is extremely low, e.g. in soils. Thus, the presence of siderophore-producing microorganisms in the rhizosphere contributes to plant health by complexing iron and making it less available to phytophathogens that are generally not able to produce comparable Fe-transport systems [40].

In addition to peptides, polyketides are the other dominant family of secondary metabolites having revelant bioactivities. Similarly to B. amyloliquefaciens FZB42, three functional gene clusters directing the synthesis of difficidin, macrolactin and bacillaene were identified in strain GA1. Difficidin is an unsaturated 22-membered macrocylic polyene lactone phosphate ester [41] with broad spectrum antibacterial activity [42]. It inhibits protein biosynthesis [43] and was recently shown promising in its suppressive action against Erwinia amylovara, a devasting plant pathogen causing necrotrophic fire blight disease of apple, pear and other rosaceous plants [6]. By contrast, macrolactin and bacillaene have not yet been demonstrated to be directly related to biocontrol, although they are both antimicrobial agents that could be potentially useful in human medicine. Macrolactin, which consists of a 24-membered ring lactone, had the ability to inhibit murine melanoma cancer cells as well as mammalian her- pes simplex viruses. It was also shown effective in protecting lymphoblast cells from HIV [44]. Similarly to difficidin, bacillaene is an inhibitor of prokaryotic protein synthesis constituted by an open-chain enamine acid with an extended polyene system. This compound displays antimicrobial activity toward human pathogens such as Serratia marcescens, Klebsiella pneumoniae and Staphylococcus aureus [45].

Bacilysin is a dipeptide composed of an L-alanine and the unusual amino acid L-anticapsin and represents one of the simplest peptide antibiotics known with antifungal and antibacterial activities [46]. L-anticapsin, released after uptake in susceptible cells, is an inhibitor of the glucose amine-6-phosphate synthetase, an enzyme essential in cell wall biosynthesis [47]. Due to its antibacterial activity, bacilysin is effective as a biocontrol agent, notably by inhibiting the growth of E. amylovora, the causative agent of fire blight disease [6]. It is also effective on the Absidia $s s p$. , which is responsible for cutaneous and invasive zygomycosis in immunocompromised patients [48]. Besides bacilysin, some strains of $B$. subtilis also co-produced chlorotetaine, a chlorinated derivative of bacilysin with similar antibacterial activity [20,49]. Although no direct evidences are available, some experimental data suggest that the two compounds could share the same biosynthetic pathway [50]. Here, mass spectrometry analysis demonstrated that B. amyloliquefaciens GA1 synthetises only chlorotetaine as dipeptide antibiotic. While this behaviour is not clearly understood, this is to our knowledge the first B. amyloliquefaciens strain reported to produce chlorotetaine and the first strain to produce chlorotetaine and not bacilysin.

\section{Conclusion}

In conclusion, the genetic and biochemical characterisation of the plant-associated B. amyloliquefaciens GAI demonstrated that the strain possesses a huge potential for biocontrol and plant growth promotion. Its natural competence and its possible genetic manipulation render strain GA1 attractive for further investigations for the development of green pesticides.

\section{Methods \\ Strain indentification}

Strain GA1 was identified by $r e c A$ and $r e c N$ sequence analysis [22]. Extraction and amplification of genomic DNA were performed as described elsewhere [51]. Fragments of $r e c A$ and $r e c N$ were amplified using primer pairs recAf/ recAr and recNf/recNr, respectively (Table 2) and sequenced at the GIGA Genomics Facility (University of Liege, Liege, Belgium). Based on the 372 bp and 849 bp partial sequences of $r e c N$ and $r e c A$, phylogenetically related bacteria were aligned using BLAST search against the GenBank data base. Multiple alignments with the 
Table 2: Oligonucleotides used in this study

\begin{tabular}{|c|c|c|}
\hline Name & Sequence 5'-3' & Metabolite, gene or flanking region \\
\hline bacAFI & GTGAAGGCCGTACTTTTGTCTGGC & Bacilysin, right \\
\hline bacARI & GGGGGGAAATACAGCTTCAGGGC & Bacilysin, right \\
\hline beaBFI & GCCCGAAACGGCAGCGCCTG & Bacillaene, left \\
\hline beaBRI & CGGAATGGAGGCTTTGATCCTCTG & Bacillaene, left \\
\hline beaSFI & CGCAAAAGCTCTTCGACCGCCGTC & Bacillaene, right \\
\hline beaSRI & CTCTCGTGCCGTCGGAATATCCGC & Bacillaene, right \\
\hline dfnMFI & CGGAGTGAAACCGTGCCGGGATAAAGA & Difficidin, left \\
\hline dfnMRI & GACCATTCAGAGCGGAAAGCTCC & Difficidin, left \\
\hline dfnAFI & GGTGCGGCATGAAGATTTGAGATCACCG & Difficidin, right \\
\hline dfnARI & GGAGAGCACTTCAATTCCGACGTTGACC & Difficidin, right \\
\hline dhbFF3 & GCCTAGATGACATGGCGGCGG & Bacillibactin, left \\
\hline dhbFR2 & GCCGCCGTAGTCGTCCGTGAAGACCG & Bacillibactin, left \\
\hline dhbAFI & CGCCTAAAGTAGCGCCGCCATCAACGC & Bacillibactin, right \\
\hline dhbAR2 & CCGCGATGGAGCGGGATTATCCG & Bacillibactin, right \\
\hline fenAFI & CCTCGCTCCGCATGATCTTTTGG & Fengycin, left \\
\hline fenARI & CGGGAGCACGGTGGCAATGTG & Fengycin, left \\
\hline fenEFI & GTTTCATGGCGGCGAGCACG & Fengycin, right \\
\hline fenERI & GATTCGCGGGAAGCGGATTGAGC & Fengycin, right \\
\hline ituF4 & CTGCCTGCGTATATGATTCCGGC & Iturin A, left \\
\hline ituR3 & CCGTGATGATGCCGTTCTTCAATCC & Iturin A, left \\
\hline ituFI & CGCCCGTGAAGGAGCAGCCG & Iturin A, right \\
\hline ituRI & GCCAGGAAGCGGGGCTTCAC & Iturin A, right \\
\hline $\mathrm{mlnAFI}$ & CGGCTGCGGGGGAAAAGATCCG & Macrolactin, left \\
\hline$m \ln A R I$ & CAGCATCAGGGCGTGTATGACCTTC & Macrolactin, left \\
\hline mlnIFI & GGAAGAAAAACAGTCGAGGCGATGCTG & Macrolactin, right \\
\hline$m \ln \mid R I$ & GAGAAGCTCCGCCGTCACCAGTG & Macrolactin, right \\
\hline srfAAFI & GCCCGTGAGCCGAATGGATAAG & Surfactin, left \\
\hline srfAARI & CCGTTTCAGGGACACAAGCTCCG & Surfactin, left \\
\hline srfADFI & CCGTTCGCAGGAGGCTATTCC & Surfactin, right \\
\hline srfADR I & CGCCCATCCTGCTGAAAAAGCG & Surfactin, right \\
\hline ywfGFI & GAAGAGATCCTCGCCAAACATCCGG & Bacilysin, left \\
\hline ywfGRI & GAGCGGATTGATCCCGCCGTC & Bacilysin, left \\
\hline nrsARI & GGAGGAGCTAATGACCCATCC & $n r s A B$ \\
\hline nrsBF2 & CTCCTATGGAGCACGATCCAAC & $n r s A B$ \\
\hline nrsCFI & GGAATGCTGGTCCATTCAGCC & $n r s C$ \\
\hline nrsCRI & CAATCGCCAGTATCCTCGCAG & nrsC \\
\hline nrsDFI & CCCAACTTATTTCACCGCCC & $n r s D$ \\
\hline nrsDRI & GTAAGGCTCGGCATTGAATCGAG & $n r s D$ \\
\hline nrsEFI & GGTGTGAAATCGTTGCGTTGG & nrsED \\
\hline nrsERI & CAACAGGTAGCGTATGCGTGC & $n r s E D$ \\
\hline nrsFFI & CGTACAGCCGGGCCAACTTCAAC & $n r s F$ \\
\hline nrsFRI & GGGCGTGCATATTAGGTGGAATC & $n r s F$ \\
\hline recAf & TGAGTGATCGTCAGGCAGCCTTAG & recA \\
\hline recAr & TTCTTCATAAGAATACCACGAACCGC & recA \\
\hline $\mathrm{recNf}$ & CTTTTGCGATCAGAAGGTGCGTATCCG & $\mathrm{recN}$ \\
\hline $\mathrm{recNr}$ & GCCATTATAGAGGAACTGACGATTTC & $\operatorname{recN}$ \\
\hline $\mathrm{mrsF} 2$ & CTTGTGCCAATTCCCGGCTGAC & $m r s K 2$ \\
\hline mrsRI & GGATGGCCGGTGTCTCACATG & $m r s K 2$ \\
\hline $\mathrm{mrsF} 3$ & CCATCGGTTTTCCCCATACCCATG & $m r s K 2 R 2$ \\
\hline mrsR2 & GTGGGGGGAGTTTTATGGCGGAG & $m r s K 2 R 2$ \\
\hline mrsF4 & GGTGAAGCCATCAGTGTCCGG & $m r s R 2$ \\
\hline mrsR3 & CCAGCACCATTCGGTCCAAGAAAACC & $m r s R 2$ \\
\hline mrsF5 & GTGGCTGTCTCAAACAGAACCGG & $m r s G$ \\
\hline mrsR4 & GTTGCGGCTAATGGAAAACCCAGACC & $m r s G$ \\
\hline $\mathrm{mrsF} 6$ & GGGCCTTTGTTAGGTGTATCCCTGG & $m r s E$ \\
\hline mrsR5 & GGAAGACTCCCGCTTATGCCTAAC & $m r s E$ \\
\hline mrsF7 & CCAGTGAACATGAGGAGCCC & $m r s E-f b a b B$ \\
\hline mrsR6 & CGCGATGACAAAAGAAGTCGCCG & $m r s E-f b a b B$ \\
\hline sboAl & CTTCATTTGTTCCGCAATGTTCA & sboA \\
\hline sboA2 & CCCAGTGGGCCAATTGAATCCTCCC & $s b o A$ \\
\hline ablBI & CGCGCAAGTAGTCGATTTCTAACA & albA \\
\hline ablB2 & CAAGTTTGGGCAAAAGAGCTTTTTC & albA \\
\hline
\end{tabular}


rec N-recA concatenated sequences of related species of the genus Bacillus were implemented using MUSCLE software [52]. A maximum likelihood phylogenetic tree was constructed by the parsinomy method using PAUP* software (version 4.0b8, [53]) and the sequence from Clostridium botulinum KBAB4 as outgroup. The parameters used for tree construction were as follows: (i) model of nucleotide substitution: GTR plus gamma distribution; (ii) number of substitution rate categories: 6; (iii) rate matrix parameter: estimated by program; (iv) number of bloodstrap replicates: 100.

\section{Genome characterisation}

For partial genome sequencing, a random shotgun approach was used. Total genomic DNA from strain GA1 was shared by nebulisation according to Surzycki [54]. DNA fragments of 2-3 kb in size were cloned into pMOSblue (GE Healthcare, Uppsala, Sweden) to establish a shotgun library. The inserts of 500 recombinant plasmids were sequenced from both ends. Sequences were processed with Vector NTI software (Invitrogen) and similarity search was performed using BLAST algorithm against the GenBank database. The chromosomic location of the different gene clusters identified in strain GAI was performed by sequencing their flanking regions using the FZB42 genomic sequence [13] as a template for PCR primer design (Table 2). The nrsF, nrsE, nrsD, nrsC, nrsAB, mrsK2, $m r s R 2, m r s G, m r s E, f b a B, s b o A$ and albA gene fragments were amplified by PCR using the primer pairs listed in Table 1 and genomic DNA from $B$. amyloliquefaciens strains FZB42 and GA1 or from B. subtilis 168 as a template.

\section{Identification of NRPS and PKS metabolites}

For polyketide and lipopeptide production, B. amyloliquefaciens GAI was grown in Landy medium [55] at $37^{\circ} \mathrm{C}$ for $12 \mathrm{~h}$ and $72 \mathrm{~h}$, respectively. Samples were extracted from the culture supernatant by solid phase extraction using Chromafix C18ec cartridge (Machery-Nagel, Duren, Germany). After binding and subsequent washing steps with MilliQ water (5 bed volume), metabolites were eluted with methanol ( 2 bed volume), dried under vacuum and resuspended in $100 \mu \mathrm{l}$ of methanol. The resulting samples were analysed by reverse-phase high pressure liquid chromatography (Waters Alliance 2695/diode array detector) coupled with single quad mass spectrometer (Waters SQD mass analyser) on an X-Terra MS 150*2.1 mm, $3.5 \mu \mathrm{m}$ column (Waters). Lipopeptides were eluted as described elsewhere [15] whereas polyketides were eluted in a binary solvent system (solvent A: water-0.1\% formic acid, solvent B: acetonitrile- $0.1 \%$ formic acid) as follows: $30 \%$ B for 5 min followed by a 5 min gradient from 30\% B to $45 \% \mathrm{~B}$ and a subsequent $25 \mathrm{~min}$ gradient from $45 \% \mathrm{~B}$ to $100 \% \mathrm{~B}$ at a flow rate of $0.5 \mathrm{ml} / \mathrm{min}$ at $40^{\circ} \mathrm{C}$. The identity of each metabolite was obtained on the basis of the mass of molecular ions detected in the SQD by setting electrospray ionisation (both positive and negative mode) conditions in the MS as source temperature, $150{ }^{\circ} \mathrm{C}$; desolvatation temperature, $325^{\circ} \mathrm{C}$; nitrogen flow, $550 \mathrm{l} /$ min; cone voltage $80 \mathrm{~V}$. Matrix-assisted laser desorption ionisation time of flight (MALDI-TOF) mass spectrometry was performed on the crude culture supernatant on a Bruker Ultraflex TOF spectrometer (Bruker Daltonics) as described elsewhere [56]. Siderophore production was evaluated using the chrome-azurol-sulphonate (CAS) agar plate assay [57] using the growth medium described previously [58].

\section{Indentification of ribosomaly synthetised peptide}

The ribosomaly synthetised peptide antibiotics were obtained by growing strain GA1 in Basic 77 medium [59] for $22 \mathrm{~h}$. Peptides were extracted from freeze-dried culture filtrate with $30 \%$ acetonitrile- $0.1 \%$ formic acid before being analysed by HPLC-ESI mass spectrometry. Molecule were eluted at a flow rate of $0,2 \mathrm{ml} / \mathrm{min}$ of a water/acetonitrile/formic acid mixture $(87 / 12,9 / 0,1 \mathrm{v} / \mathrm{v} / \mathrm{v})$ and their identity was obtained on the basis of the mass of the molecular ions detected in the SQD by setting electrospray ionization (positive mode) condition in the MS as source temperature, $150^{\circ} \mathrm{C}$; desolvatation temperature, $300^{\circ} \mathrm{C}$; nitrogen flow, $550 \mathrm{l} / \mathrm{min}$; cone voltage, $80 \mathrm{~V}$. MALDI-TOF mass spectrometry was used in the reflectron mode of detection and with $\alpha$-cyano-4-hydroxy-cinnamic acid as matrix.

\section{Competing interests}

The authors declare that they have no competing interests.

\section{Authors' contributions}

AA performed part of the genome characterisation and cultures for LC-MS analysis. MO performed the LC-MS analysis. BH constructed the shotgun library and annotated the sequence. $\mathrm{AB}$ and $\mathrm{BJ}$ planed and supervised part of the experiments. YL performed the phylogenetic analysis. PF wrote the final version of the manuscript and supervised the work. All authors approved the final version of the manuscript.

\section{Acknowledgements}

A. Arguelles-Arias and Y. Lara are recipients of a FRIA grant (Fonds pour la Formation dans la Recherche et l'Agriculture, Belgium). P. Fickers and M. Ongena are post-doctoral researcher and research associate, respectively at the FRS-FNRS (Fonds National de la Recherche Scientifique, Belgium). This work received financial support from the program Crédits aux Chercheurs NoI.5.192.08F (FRS-FNRS, Belgium).

\section{References}

I. Tournas V: Spoilage of vegetable crops by bacteria and fungi and related health hazards. Critical review in microbiology 2005, 3I:33-44.

2. Lucy M, Reed E, Glick BR: pplications of free living plant growthpromoting rhizobacteria. Antonie Van Leeuwenhoek 2004, 86:AI-25. 
3. Somers E, Vanderleyden J, Srinivasan M: Rhizosphere bacterial signalling: a love parade beneath our feet. Critical review of microbiology 2004, 30:205-240.

4. Lugtenberg BJ, Kamilova F: Plant-Growth-Promoting Rhizobacteria. Annual review of microbiology 2009, 63:54I-556.

5. Leclere V, Bechet M, Adam A, Guez JS, Wathelet B, Ongena M, Thonart P, Gancel F, Chollet-Imbert M, Jacques P: Mycosubtilin overproduction by Bacillus subtilis BBG 100 enhances the organism's antagonistic and biocontrol activities. Applied and environmental microbiology 2005, 7 I:4577-4584.

6. Chen X, Scholz R, Borriss M, Junge H, Mogel G, Kunz S, Borriss R: Difficidin and bacilysin produced by plant-associated Bacillus amyloliquefaciens Dare efficient in controlling fire blight disease. Journal of biotechnology 2009, 140:38-44.

7. Senghor A, Liang WL, Ho W: Integrated control of Colletotrichum gloeosporioides on mango fruit in Taiwan by the combination of Bacillus subtilis and fruit bagging. Biocontrol science and technology 2007, 9:575-580.

8. Yang Z, Guo H, Zhang X: Study on the control of peach postharvest diseases using Bacillus subtilis. China Fruits 2008, 23:35-38.

9. Kotan R, Dikbas N, Bostan H: Biological control of post harvest disease caused by Aspergillus flavus on stored lemon fruits. African journal of biotechnology 2009, 8:209-2।4.

10. Favel D: Commercialization and implementation of biocontrol. Annual review of phytopathology 2005, 43:A337-359.

II. Loper JE, Buyer JS: Siderophores in microbial interactions on plant-surfaces. Molecular plant microbe interactions 1991, 4:5-13.

12. Stein T: Bacillus subtilis antibiotics: structures, syntheses and specific functions. Molecular microbiology 2005, 56:845-857.

13. Chen X, Koumoutsi A, Scholz R, Eisenreich A, Schneider K, Heinemeyer I, Morgenstern B, Voss B, Hess W, Reva O, Junge H, Voigt B, Jungblut $P$, Vater J, Sussmuth $R$, Liesegang $H$, Strittmatter $A$, Gottschalk G, Borriss R: Comparative analysis of the complete genome sequence of the plant growth-promoting bacterium Bacillus amyloliquefaciens FZB42. Nature biotechnology 2007, 25: $1007-1014$

14. Chen X, Koumoutsi A, Scholz R, Schneider K, Vater J, Sussmuth R, Piel J, Borriss R: Genome analysis of Bacillus amyloliquefaciens FZB42 reveals its potential for biocontrol of plant pathogens. Journal of biotechnology 2009, I 40:27-37.

15. Toure $Y$, Ongena M, Jacques $P$, Guiro A, Thonart P: Role of lipopeptides produced by Bacillus subtilis GAI in the reduction of grey mould disease caused by Botrytis cinerea on apple. Journal of applied microbiology 2004, 96: I I5 I-I I60.

16. Tsuge K, Akiyama T, Shoda M: Cloning, sequencing, and characterization of the iturin A operon. Journal of bacteriology 200I, 1 83:6265-6273.

17. Sutyak KE, Wirawan R, Aroutcheva A, Chikindas M: Isolation of the Bacillus subtilis antimicrobial peptide subtilosin from the dairy product-derived Bacillus amyloliquefaciens. Journal of applied microbiology 2008, 104: 1067-1074.

18. Chen X, Vater J, Piel J, Franke P, Scholz R, Schneider K, Koumoutsi A, Hitzeroth G, Grammel N, Strittmatter A, Gottschalk G, Sussmuth R, Borriss R: Structural and functional characterization of three polyketide synthase gene clusters in Bacillus amyloliquefaciens FZB42. Journal of bacteriology 2006, 188:4024-4036.

19. Schneider K, Chen X, Vater J, Franke P, Nicholson G, Borriss R, Sussmuth $\mathrm{R}$ : Macrolactin is the polyketide biosynthesis product of the pks2 cluster of Bacillus amyloliquefaciens FZB42. Journal of natural product 2007, 70:1417-1423.

20. Rapp C, Jung G, Katzer W, Loeffer W: Chlorotetain from Bacillus subtilis, an antifungal dipeptide with an unusual chlorine containing amino acid. Angewandte chemie interationnal edition 1988, I 2:1733-1734.

21. Porwal S, Lal S, Cheema S, Kalia VC: Phylogeny in aid of the present and novel microbial lineages: diversity in Bacillus. PLoS One 2009, 4:e4438.

22. Zeigler $D$ : Gene sequences useful for predicting relatedness of whole genomes in bacteria. International journal of systematic and evolutionary microbiology 2003, 53:1893-1900.

23. Meier JL, Burkart MD: The chemical biology of modular biosynthetic enzymes. Chemical society review 2009, 38:T20I2-2045.

24. Banat I, Makkar R, Cameotra S: Potential commercial applications of microbial surfactants. Applied microbiology and biotechnology 2000, 53:495-508.
25. Singh P, Cameotra S: Enhancement of metal bioremediation by use of microbial surfactants. Biochemistry and Biophysical Research Communication 2004, 3 19:291-297.

26. Ron E, Rosenberg E: Natural roles of biosurfactants. Environmental microbiology 200I, 3:229-236.

27. Mulligan C: Environmental applications for biosurfactants. Environmental pollution 2005, 133:183-198.

28. Ongena M, Jacques P: Bacillus lipopeptides: versatile weapons for plant disease biocontrol. Trends in microbiology 2008, 16: $115-125$

29. Danhorn T, Fuqua C: Biofilm formation by plant-associated bacteria. Annual review of microbiology 2007, 61:40I-422.

30. Kinsinger R, Shirk M, Fall R: Rapid surface motility in Bacillus subtilis is dependent on extracellular surfactin and potassium ion. Journal of bacteriology 2003, 185:5627-563I.

3I. Bais H, Fall R, Vivanco JM: Biocontrol of Bacillus subtilis against infection of Arabidopsis roots by Pseudomonas syringae is facilitated by biofilm formation and surfactin production. Plant physiology 2004, 134:307-319.

32. Hofemeister J, Conrad B, Adler B, Hofemeister B, Feesche J, Kucheryava N, Steinborn G, Franke P, Grammel N, Zwintscher A, Leenders F, Hitzeroth G, Vater J: Genetic analysis of the biosynthesis of non-ribosomal peptide- and polyketide-like antibiotics, iron uptake and biofilm formation by Bacillus subtilis AI/3. Molecular genetic and genomics 2004, 272:363-378.

33. Leclere V, Marti R, Bechet M, Fickers P, Jacques P: The lipopeptides mycosubtilin and surfactin enhance spreading of Bacillus subtilis strains by their surface-active properties. Archives of microbiology 2006, I 86:475-483.

34. Maget-Dana R, Thimon L, Peypoux F, Ptak M: Surfactin/iturin A interactions may explain the synergistic effect of surfactin on the biological properties of iturin A. Biochimie 1992, 74:1047-105I.

35. Asaka O, Shoda M: Biocontrol of Rhizoctonia solani dampingoff of tomato with Bacillus subtilis RB I 4. Applied and environmental microbiology 1996, 62:408I-4085.

36. Romero D, de Vicente A, Rakotoaly R, Dufour S, Veening J, Arrebola E, Cazorla F, Kuipers O, Paquot M, Perez-Garcia A: The iturin and fengycin families of lipopeptides are key factors in antagonism of Bacillus subtilis toward Podosphaera fusca. Molecular plant microbe interactions 2007, 20:430-440.

37. Ongena M, Jourdan E, Adam A, Paquot M, Brans A, Joris B, Arpigny $J L$, Thonart P: Surfactin and fengycin lipopeptides of Bacillus subtilis as elicitors of induced systemic resistance in plants. Environmental microbiology 2007, 9: 1084-1090.

38. Conrath U, Beckers G, Flors V, Garcia-Agustin P, Jakab G, Mauch F, Newman M, Pieterse C, Poinssot B, Pozo M, Pugin A, Schaffrath U, Ton J, Wendehenne D, Zimmerli L, Mauch-Mani B: Priming: getting ready for battle. Molecular plant microbe interaction 2006, 19:1062-1071.

39. Jourdan E, Henry G, Duby F, Dommes J, Barthelemy JP, Thonart P, Ongena M: Insights into the defense-related events occurring in plant cells following perception of surfactin-type lipopeptide from Bacillus subtilis. Molecular plant microbe interactions 2009 , 22:456-468

40. Kloepper J, Leong J, Teinzte M, Schroth M: Pseudomonas siderophore: a mechanism explaining disease-suppressive soil. Current microbiology 1980, 4:317-320.

4I. Wilson K, Flor J, Schwartz R, Joshua H, Smith J, Pelak B, Liesch JM, Hensens $O$ : Difficidin and oxydifficidin: novel broad spectrum antibacterial antibiotics produced by Bacillus subtilis. II. Isolation and physico-chemical characterization. Journal of antibiotic (Tokyo) 1987, 40:1682-1691.

42. Zimmerman S, Schwartz C, Monaghan R, Pelak B, Weissberger B, Gilfillan E, Mochales S, Hernandez S, Currie S, Tejera E: Difficidin and oxydifficidin: novel broad spectrum antibacterial antibiotics produced by Bacillus subtilis. I. Production, taxonomy and antibacterial activity. Journal of antibiotic (Tokyo) 1987, 40:1677-I68I.

43. Zweerink M, Edison A: Difficidin and oxydifficidin: novel broad spectrum antibacterial antibiotics produced by Bacillus subtilis. III. Mode of action of difficidin. Journal of antibiotic (Tokyo) 1987, 40:1692-1697.

44. Gustafson K, Roman M, Fenical W: The macrolactin, a novel class of antiviral and cytotoxic macrolides from a deep-sea marine 
bacterium. Journal of the american chemical society 1989 , I I I:7519-7524.

45. Patel PS, Huang S, Fisher S, Pirnik D, Aklonis C, Dean L, Meyers E, Fernandes P, Mayerl F: Bacillaene, a novel inhibitor of procaryotic protein synthesis produced by Bacillus subtilis: production, taxonomy, isolation, physico-chemical characterization and biological activity. Journal of antibiotic (Tokyo) 1995, 48:997-1003.

46. Kenig M, Abraham E: Antimicrobial activities and antagonists of bacilysin and anticapsin. Journal of general microbiology 1976, 94:37-45.

47. Chmara $\mathrm{H}$ : Inhibition of glucosamine synthase by bacilysin and anticapsin. Journal of general microbiology 1985, I 3 I:265-27I.

48. Righi E, Giacomazzi CG, Bassetti M, Bisio F, Soro O, McDermott JL, Varnier OE, Ratto S, Viscoli C: Soft-tissue infection with Absidia corymbifera and kidney complications in an AIDS patient. Medical Mycology 2007, 45:637-640.

49. Phister TG, O'Sullivan DJ, McKay L: Identification of bacilysin, chlorotetaine, and iturin a produced by Bacillus sp. strain CS93 isolated from pozol, a Mexican fermented maize dough. Applied and environmental microbiology 2004, 70:631-634.

50. Yazgan A, Ozcengiz G, Marahiel M: Tn I O insertional mutations of Bacillus subtilis that block the biosynthesis of bacilysin. Biochimica biophysica Acta 200I, I5 I 8:87-94.

5I. Fickers P, Leclere V, Guez JS, Bechet M, Coucheney F, Joris B, Jacques $P$ : Temperature dependence of mycosubtilin homologue production in Bacillus subtilis ATCC6633. Research in microbiology 2008, I 59:449-457.

52. Edgar R: MUSCLE: multiple sequence alignment with high accuracy and high throughput. Nucleic acids research 2004, 32: $1792-1797$

53. Swofford D, Waddell P, Huelsenbeck J, Foster P, Lewis P, Rogers J: Bias in phylogenetic estimation and its relevance to the choice between parsimony and likelihood methods. Systematic biology 200I, 50:525-539.

54. Surzycki S: A fast method to prepare random fragment sequencing libraries using a new procedure of DNA shearing by nebulization and electroporation. In Human molecular biology laboratory manual, 2003 Edited by: Surzycki S. Oxford: Blackwell; 1990:100-106.

55. Landy M, Warren GH, Rosenman SB, Colio LG: Bacillomycin: an antibiotic from Bacillus subtilis active against pathogenic fungi. Proceedings of the Society for Experimental Biology and Medicine 1948, 67:539-541.

56. Fickers $P$, Guez JS, Damblon $C$, Leclere $V$, Bechet $M$, Jacques $P$, Joris $B$ : High-level biosynthesis of the anteiso- $C(17)$ isoform of the antibiotic mycosubtilin in Bacillus subtilis and characterization of its candidacidal activity. Applied and environmrental microbiology 2009, 75:4636-4640.

57. Schwyn B, Neiland JB: Universal chemical assay for the detection and determination of siderophores. Analytical biochemistry 1987, 160:47-56.

58. Miethke M, Westers H, Blom EJ, Kuipers OP, Marahiel MA: Iron starvation triggers the stringent response and induces amino acid biosynthesis for bacillibactin production in Bacillus subtilis. Journal of bacteriology 2006, 188:8655-8657.

59. Phister T, O'Sullivan D, McKay L: Identification of bacilysin, chlorotetain and iturin produced by Bacillus sp. Strain CS93 isolated from pozol, a Mexican fermented maize dough. Applied and environmental microbiology 2004, 70:631-634.
Publish with BioMed Central and every scientist can read your work free of charge

"BioMed Central will be the most significant development for disseminating the results of biomedical research in our lifetime. "

Sir Paul Nurse, Cancer Research UK

Your research papers will be:

- available free of charge to the entire biomedical community

- peer reviewed and published immediately upon acceptance

- cited in PubMed and archived on PubMed Central

- yours - you keep the copyright

Submit your manuscript here:

http://www.biomedcentral.com/info/publishing_adv.asp
BiolMedcentral 